\title{
Avaliação de um Jogo Digital para o Ensino de Vocabulário Receptivo com Estudantes Público-Alvo da Educação Especial
}

\author{
Title: Evaluation of a Digital Game for Teaching Receptive Vocabulary with Special \\ Education Students
}

\author{
Lincoln Satoru Sossida Sassaki \\ Universidade Federal do ABC \\ satorusassaki@gmail.com
}

\author{
Priscila Benitez \\ Centro de Matemática, \\ Computação e Cognição da \\ Universidade Federal do ABC \\ priscila.benitez@ufabc.edu.br
}

\author{
André Luiz Brandão \\ Centro de Matemática, \\ Computação e Cognição da \\ Universidade Federal do ABC \\ andre.brandao@ufabc.edu.br
}

\begin{abstract}
Resumo
A aplicação de jogos digitais sérios tem favorecido tanto o ensino de vocabulário receptivo como a interação humano-computador para estudantes com diversos repertórios comportamentais, sendo considerado um recurso de Tecnologia Assistiva (TA) que fomenta a aprendizagem de vocabulário receptivo e pode incrementar o ensino no Atendimento Educacional Especializado (AEE). O estudo teve como objetivo avaliar se o uso de um jogo digital sério seria suficiente para avaliar e ensinar vocabulário receptivo, em uma situação naturalística, a partir da perspectiva do professor do AEE, com estudantes com repertórios comportamentais variados (como nos casos de deficiência intelectual, síndrome de Down, transtorno do espectro autista e paralisia cerebral). O jogo foi aplicado com oito estudantes. O procedimento de ensino foi constituido por quatro fases: verificou-se o interesse e disponibilidade da professora do AEE para participar do projeto; aplicou-se o pré-teste, em que os estudantes jogaram sem nenhuma instrução adicional; os alunos jogam com acompanhamento e dicas da professora do AEE; e, por último, os estudantes jogaram sem nenhuma instrução adicional (pós-teste), e foi avaliada a percepção da professora em relação ao jogo. Cinco estudantes foram excluidos por apresentarem desempenho máximo no préteste. Os resultados evidenciaram que o jogo pode servir enquanto recurso a ser aplicado no AEE, pelos professores da Educação Especial, nas escolas regulares, além de ensinar vocabulário receptivo para os estudantes com deficiência e transtorno.
\end{abstract}

Palavras-Chave: Atendimento Educacional Especializado; Desenho Universal; Educação Inclusiva; Público-alvo da educação especial; Tecnologia Assistiva; Vocabulário Receptivo

\begin{abstract}
The application of digital games has favored either the teaching of receptive vocabulary as human-computer interaction for students with diverse behavioral repertories, which characterizes it as an Assistive Technology's resource (AT) that promotes receptive vocabulary learning and increases the Specialized Educational Services' teaching (SES). The aim of this study was to assess whether using a serious digital game would be sufficient to assess and teach receptive vocabulary, in a naturalistic situation, from the perspective of the SES teacher, with students with varied behavioral repertoires (such as intellectual disability, Down syndrome, autism spectrum disorder and paralysis brain). The teaching procedure consisted of four phases. The first phase involved verifying the interest and availability of the SES teacher to participate in the project. The second phase encompassed the application of the pretest, in which the students played without any further instruction. Following, an SES teacher played along with each student, providing additional tips. Finally, the students played without any further instruction (post-test) and were assessed by the teacher's perception of the game. Five students achieved 100\% performance in the pretest and, therefore, do not participate in the other phases of the study. The results showed that the game can serve while being used in the SES by Special Education teachers in mainstream schools, plus the use of receptive vocabulary for students with problems and disorders.

Keywords: Specialized Educational Service; Universal design; Inclusive education; Assistive technology; Receptive Vocabulary; Students of special education

Cite as: Sassaki, L. S. S.; Benitez, P. \& Brandão, A. L. (2020). Evaluation of a Digital Game for Teaching Receptive Vocabulary with Special Education Students (Avaliação de um Jogo Digital para o Ensino de Vocabulário Receptivo com Estudantes Público-Alvo da Educação Especial). Brazilian Journal of Computers in Education (Revista Brasileira de Informática na Educação - RBIE), 28, 626-643. DOI: 10.5753/RBIE.2020.28.0.626
\end{abstract}




\section{Introdução}

O conhecimento popular em relação à importância da educação escolar, principalmente para as crianças, é corroborado e defendido por estudiosos da área de desenvolvimento infantil. Entretanto o ponto de divergência entre ambos se dá no âmbito da função escolar: para o conhecimento popular, a escola possui como objetivo central a disseminação do conhecimento científico; já para estudiosos, a escola ultrapassa tal saber, juntamente com a esfera familiar, por serem responsáveis pela formação de sujeitos autônomos e atuantes criticamente em suas comunidades locais (Rosa, 2001).

Define-se sujeito autônomo, segundo Freire (1996), aquele que tem condições de reconhecer-se no meio, assim como mudá-lo de forma intencional, o que significa que se torna requisito mínimo que o estudante tenha plenas condições de interpretação de sua realidade. Desse modo, assim como alguns outros pontos, esse requisito é garantido na legislação brasileira como, por exemplo: Lei n ${ }^{\circ}$ 9.394, Cap. 2, Seção I, Art. 22, a qual diz "a educação básica tem por finalidades desenvolver o educando, assegurar-lhe a formação comum indispensável para o exercício da cidadania e fornecer-lhe meios para progredir no trabalho e em estudos posteriores" (Brasil, 1996).

As condições mínimas de acesso ao processo de escolarização devem ser disponibilizadas a todas as pessoas, incluindo o público-alvo da educação especial (estudantes com deficiência, transtornos globais do desenvolvimento e altas habilidades/superdotação), delineado na Política Nacional de Educação Especial na perspectiva da Educação Inclusiva (Brasil, 2008). No Capítulo 5, da Lei no 12.796, referente à Educação Especial, está respaldado no artigo $4^{\circ}$, inciso III, o direito ao "atendimento educacional especializado (AEE) gratuito aos educandos com deficiência, transtornos globais do desenvolvimento e altas habilidades ou superdotação, transversal a todos os níveis, etapas e modalidades, preferencialmente na rede regular de ensino" (Brasil, 1996, atualizado em 2013), que garante a atuação do AEE no contraturno do horário regular da escola, com o objetivo de trabalhar as barreiras educacionais que dificultam a permanência em sala de aula comum. Para tal, é necessário que o professor realize uma avaliação para identificar as devidas barreiras educacionais de modo a superá-las por meio de um planejamento educacional individualizado.

Assim, o processo inclusivo dos estudantes público-alvo da educação especial tem ocasionado reflexões sobre as estratégias adotadas nesse escopo, tais quais os benefícios proporcionados a cada estudante. Para garantir o acesso e a permanência de um estudante na escola regular é necessário, basicamente, criar condições para a promoção do ensino e aprendizagem de conteúdos sociais e pedagógicos. Para que isso ocorra é necessário envolver os diferentes professores presentes nesse processo como, por exemplo, o professor de educação especial, responsável pela oferta do AEE na escola comum, em contraturno (Benitez \& Domeniconi, 2016). Garantir a inclusão de qualquer estudante, a partir do trabalho conjunto com o professor de educação especial, significa ampliar as possibilidades de permanência desse público-alvo na escola regular, o que poderia suprir as demandas reducionistas que primam apenas pela oferta de vagas e recursos físicos como únicos elementos para a inclusão (Espote, Serralha, \& Scorsolini-Comin, 2013).

Dentre os desafios identificados no processo inclusivo dos estudantes público-alvo da educação especial destacam-se questões relacionadas à comunicação (Togashi, \& Walter, 2016). Mendes (2019) identificou programas educacionais específicos destinados a tal público, dentre eles, um conjunto de programas efetivamente distintos de práticas pedagógicas convencionais no contexto escolar com base em estratégias de ensino de comunicação. Camargo (2017) 
também defende a importância de estratégias que atendam os processos de comunicação que contemplem a todos os estudantes da sala de aula comum.

Assim, ao propor programas comunicativos, é fundamental entender o processo de aquisição da linguagem e, principalmente, do vocabulário (Armonia et al., 2015). Uma forma de ampliar o vocabulário e estabelecer estratégias de ensino pode ser por meio de atividades concatenadas ao AEE e à sala de aula comum a partir de estratégias diversificadas de ensino. No caso específico do AEE, podem ser utilizados recursos lúdicos, como jogos digitais sérios que favoreçam o desenvolvimento e ampliação de vocabulário expressivo e receptivo.

O vocabulário receptivo está relacionado ao processamento de informação e é considerado como medida fundamental para área da habilidade intelectual (Armonia et al., 2015), pois se refere a uma capacidade do estudante compreender aquilo que ele ouve e lê (Araujo et al., 2010). Uma atividade que envolve vocabulário receptivo pode ser estruturada na apresentação de objetos seguida de uma instrução; por exemplo, na presença de uma bola, o professor possa solicitá-la ao aluno, cabendo ao aluno compreender a informação, identificar o objeto solicitado, e executá-la da forma correta. A partir do ensino de identificação de objetos, conforme o exemplo dado, é possível ampliar o vocabulário receptivo dos estudantes, principalmente, do público-alvo da educação especial, além de criar condições para o ensino de habilidades mais complexas, como no caso da leitura com compreensão (Colombo, \& Cárnio, 2018; Nalom et al., 2015).

Araujo et al. (2010) avaliaram o desempenho de pré-escolares em tarefas de vocabulário receptivo e identificaram um desempenho inferior para a idade cronológica em $61 \%$ das crianças avaliadas. Os autores recomendaram a urgência de um trabalho intensificado nessa área desde a educação infantil para o desenvolvimento do potencial comunicativo. Armonia et al. (2015) comparou os desempenhos de vocabulário receptivo e expressivo em crianças com transtorno específico do desenvolvimento da fala e da linguagem. 80,95\% das crianças apresentaram o desempenho esperado para avaliação de vocabulário expressivo, enquanto $52,4 \%$ mostraram desempenho esperado para o vocabulário receptivo, reafirmando a importância de desenvolver procedimentos que visam o ensino e avaliação desse tipo de vocabulário.

Uma forma de propor procedimentos de ensino e de avaliação de tarefa específicas pode ser por meio de recursos digitais, com uso de jogos sérios, tanto em situação universitária (como Freitas e Adamatti (2016) que desenvolveu um jogo sério para ensino e aprendizagem de conteúdos relacionados ao direito do trabalho), como na educação básica (para ensino da multiplicação por estratégias de resolução com cálculos mentais - Cardoso et al., 2013). O uso de tais recursos têm sido documentado como promissor para fins de ensino e aprendizagem e, para tal, requer um desenvolvimento sistemático e interdisciplinar (Rocha et al., 2016). Dessa maneira, os jogos digitais sérios podem contribuir no desenvolvimento de habilidades fundamentais para qualquer estudante para promover $\mathrm{o}$ ensino $\mathrm{e}$ aprendizagem de comportamentos diversificados, além de servir como estratégia motivacional durante a aplicação das tarefas educacionais (Brandão, Brandão, Nascimento, Moreira, Vasconcelos \& Clua, 2010a) e de apresentarem como estratégia viável para implementação no cotidiano escolar por professores de educação especial durante o AEE.

Outro aspecto fundamental se refere à implementação do Desenho Universal (DU) na criação dos recursos educacionais que podem ser aplicados tanto na sala regular quanto no AEE. O DU é definido, segundo o Decreto Federal 5.296, artigo 8', inciso IX, como uma "concepção de espaços, artefatos e produtos que visam atender simultaneamente todas as pessoas com diferentes características antropométricas e sensoriais, de forma autônoma, segura e confortável, constituindo-se nos elementos ou soluções que compõem a acessibilidade" (Brasil, 2004), ou seja, visa com que a acessibilidade ao produto, serviço ou ambiente seja garantida sem 
quaisquer barreiras para nenhum estudante, seja este o público-alvo da criação, ou não. A Lei Brasileira de Inclusão (Brasil, 2016), em seu inciso II, do artigo $3^{\circ}$, do Capítulo 1, corrobora tal definição ao citá-lo como "concepção de produtos, ambientes, programas e serviços a serem usados por todas as pessoas, sem necessidade de adaptação ou de projeto específico, incluindo os recursos de Tecnologia Assistiva (TA)".

A TA de acordo com a referida lei (Brasil, 2016), em seu art. $3^{\circ}$, inciso III é compreendida enquanto "produtos, equipamentos, dispositivos, recursos, metodologias, estratégias, práticas e serviços que objetivem promover a funcionalidade, relacionada à atividade e à participação da pessoa com deficiência ou com mobilidade reduzida, visando à sua autonomia, independência, qualidade de vida e inclusão social". Portanto, desenvolver uma TA que visa o desenho universal da aprendizagem contribui diretamente para o estabelecimento de estratégias pedagógicas inclusivas (Zerbato \& Mendes, 2018). O estudo de Araújo et al. (2013) identificou oito trabalhos que envolviam softwares para uso na educação inclusiva a partir de uma revisão da literatura no contexto do SBIE e WIE, destes, cinco estavam direcionados para estudantes surdos, um para síndrome de Down, um para déficits motores e outro para cegueira.

Nesse escopo, foi desenvolvido o Jecripe (Brandão et al., 2010a; Brandão, Trevisan, Brandão, Moreira, Nascimento, Vasconcelos, Clua \& Mourão, 2010b; Brandão, Fernandes, Trevisan, Clua, \& Strickery, 2014) e o Jecripe 2 (Brandão, \& Joselli, 2015), que será referenciado como Jecripe 1 e 2, respectivamente. $O$ objetivo principal do Jecripe 1 é proporcionar oportunidades para crianças (entre três e sete anos de idade) trabalharem habilidades cognitivas. A imitação, percepção, motricidade fina e coordenação mão-olho foram as habilidades cognitivas selecionadas e inspiraram os ambientes lúdicos presentes no ambiente virtual. O jogo Jecripe 2 (Brandão, \& Joselli, 2015) visa trabalhar habilidades cognitivas que não foram trabalhadas no Jecripe 1. As habilidades cognitivas trabalhadas são: memória, atenção e sensibilização fonológica. Atividades lúdicas de quebra-cabeças e execução de sons são os principais elementos utilizados no jogo Jecripe 2. Tais habilidades são ensinadas a partir de tarefas que visam a ampliação do vocabulário receptivo em que o estudante é instruído a estabelecer a relação entre a instrução oral dada pelo jogo e as figuras presentes em cada cena. $\mathrm{O}$ Jecripe 1 apresenta um cenário mais infantil em comparação ao Jecripe 2 e, por essa razão somada às diferentes faixas etárias, deficiências e transtornos que se pretendia avaliar o ensino do vocabulário receptivo, o segundo foi selecionado para ser avaliado sob a luz do desenho universal da aprendizagem (Zerbato \& Mendes, 2018).

Trata-se de um jogo digital que estimula habilidades cognitivas e linguísticas fundamentais para o desenvolvimento de qualquer estudante em idade pré-escolar. As habilidades estimuladas ao longo do jogo envolvem: imitação, percepção, habilidades motoras finas, coordenação mãoolho e linguagem verbal receptiva com acesso intuitivo às atividades. Em termos de tarefa de ensino, a grande ênfase dada se refere ao vocabulário receptivo, o que significa que o estudante é instruído a encontrar objetos, animais, dentre outros estímulos, a partir de uma instrução oral dada pelo próprio jogo.

O jogo foi originalmente elaborado para atender as demandas de ensino de estudantes com síndrome de Down, com idades entre três e sete anos. A elaboração dos Jecripes contou com uma equipe multidisciplinar, a partir do envolvimento de profissionais como programadores, designers, designers de jogos e profissional da área da saúde (e.g. fonoaudiólogo) que atuavam com estudantes com deficiência. O Jecripe 2 foi financiado pelos Editais 2012 da Secretaria de Cultura do Estado do Rio de Janeiro. O cenário do jogo conta com ambientes como a praia e o sítio, e com personagens, como a família da Manu (personagem com síndrome de Down), amiguinho da praia e pescador. De maneira geral, o jogo visa estimular habilidades cognitivas que envolvem a atenção, a memória e a sensibilização fonológica. 
No estudo de Brandão et al. (2010a) foi descrita a elaboração do Jecripe 1 para tal público, considerando as habilidades citadas anteriormente. Em outra publicação (Brandão et al., 2010b) o jogo foi descrito como uma ferramenta importante para a promoção do desenvolvimento cognitivo de crianças com deficiência, no contexto da educação inclusiva, especificando características acerca da interação, comunicação e design do jogo, a partir de uma avaliação da Interação Humano-Computador. Em 2014, foram realizados três estudos acerca do Jecripe 1 envolvendo a análise pelo ponto de vista da área de Visão Computacional, assim como sobre a área de Mineração de Dados e Interação Humano-Computador. Uma questão ainda latente de resposta sobre o uso dos Jecripes se refere ao processo de aprendizagem, sobretudo a diferentes públicos-alvo, de modo a atender os princípios do DU para avaliar se as tarefas de ensino propostas modificam comportamentos e, ainda, se a aplicação em ambiente natural pode considerar os Jecripes como uma ferramenta pedagógica típica da rotina escolar.

Assim sendo, o aspecto inovador do presente estudo envolve a aplicação de um jogo digital sério - Jecripe 2 - desenvolvido e fundamentado em dados sólidos de pesquisa (Brandão, 2014), com estudantes com deficiência intelectual, síndrome de Down, transtorno do espectro autista e paralisia cerebral, com diferentes faixas etárias e modalidades de ensino, durante a realização das atividades de AEE, pelos professores de educação especial, com o propósito de avaliar o uso de tal jogo na perspectiva do professor, em seu cotidiano escolar, assim como os efeitos de aprendizagem de estudantes com repertórios comportamentais variados e analisar a interação entre professor e aluno durante a aplicação do jogo. $\mathrm{O}$ estudo teve como objetivo avaliar se o uso de um jogo digital sério seria suficiente para avaliar e ensinar vocabulário receptivo, em uma situação naturalística, a partir da perspectiva do professor do AEE, com estudantes com repertórios comportamentais variados (como no caso, deficiência intelectual, síndrome de Down, transtorno do espectro autista e paralisia cerebral).

\section{Método}

\subsection{Participantes}

A Tabela 1 caracteriza os estudantes. Para a professora, o critério estabelecido era que atuasse na sala de recursos multifuncional como professora do AEE responsável pelos estudantes participantes e apresentasse disponibilidade para participação no estudo.

A amostra foi composta por estudantes público-alvo da educação especial, assim como por uma professora responsável pelo AEE, em sala de recursos multifuncional. Foram estabelecidos dois critérios de escolha para os estudantes: a) matriculados em escolas públicas regulares, b) diagnóstico médico referente ao público-alvo da educação especial. Para a professora do AEE, o critério foi disponibilidade e interesse em participação no estudo. Ela tinha 51 anos e 31 anos de exercício do magistério, com graduação em Pedagogia. Já trabalhou na rede estadual e municipal como professora alfabetizadora, no momento estava realizando o trabalho no AEE com alunos da EJA. 
Tabela 1. Caracterização dos participantes

\begin{tabular}{ccccc}
\hline & Idade & Gênero & Ano escolar matriculado & Diagnóstico medico \\
\hline A1 & 21 & Feminino & Educação de Jovens e Adultos & $\begin{array}{c}\text { Microcefalia vera e Deficiência } \\
\text { intelectual }\end{array}$ \\
A2 & 22 & Masculino & Educação de Jovens e Adultos & $\begin{array}{c}\text { Microcefalia vera e Deficiência } \\
\text { intelectual }\end{array}$ \\
A3* & 25 & Masculino & Educação de Jovens e Adultos & $\begin{array}{c}\text { Hemofilia B e Deficiência } \\
\text { Intelectual }\end{array}$ \\
A4** & 16 & Masculino & $1^{\circ}$ ano do ensino médio & $\begin{array}{c}\text { Paralisia cerebral } \\
\text { A5** }\end{array}$ \\
\hline A6** & 16 & Masculino & $8^{\circ}$ ano do ensino fundamental & $\begin{array}{c}\text { Síndrome de Down e Deficiência } \\
\text { Intelectual Severa }\end{array}$ \\
A7** & 6 & Masculino & $9^{\circ}$ ano do ensino fundamental & $\begin{array}{c}\text { Síndrome de Down e Deficiência } \\
\text { Intelectual Severa }\end{array}$ \\
A8** & 12 & Masculino & $6^{\circ}$ ano do ensino fundamental & Transtorno do Espectro Autista \\
\hline
\end{tabular}

Legenda: * refere-se à realização parcial do ensino e ** significa que realizou apenas o pré-teste (linha de base).

\subsection{Considerações éticas}

O projeto foi aprovado pelo Comitê de Ética em Pesquisa com Seres Humanos da UFABC (CAAE: 84608818.6.0000.5594, Parecer $\mathrm{n}^{\circ}$ 2.706.019). Apesar de o projeto ser na área da educação, o que minimiza os efeitos de riscos, poderia ocorrer algum cansaço, sonolência, malestar durante a realização do jogo e, caso tais comportamentos fossem identificados, a aplicação seria interrompida imediatamente. Foi utilizado um notebook com fone de ouvido e, apesar de ser seguro, poderia acontecer dele não ligar ou, ainda, do jogo travar ao longo da aplicação. Contudo, o projeto previa benefícios como a aprendizagem de habilidades comunicativas básicas, como a identificar animais, objetos, nomear sons dos animais e outras.

\subsection{Situação e Materiais}

O Jecripe 2 fornece comandos orais e é subdivido em três grandes ambientes: sítio (H1), apartamento $(\mathrm{H} 2)$ e praia $(\mathrm{H} 3)$. Na tabela 2 foram descritas as tarefas apresentadas em cada um destes ambientes, assim como as respostas esperadas pelos estudantes.

Jogar o jogo de maneira completa significa concluir todas as atividades previstas em cada uma destas etapas. Para as análises do desempenho das habilidades comunicativas envolvidas nas atividades, o jogo foi dividido em três grandes fases, que são os quatro ambientes disponíveis. O vocabulário receptivo dos estudantes foi avaliado por diferentes tarefas identificadas na Tabela 2 e ilustradas na Figura 1.

Todas as etapas da pesquisa foram aplicadas em uma sala de recurso multifuncional, em que ocorreu os AEEs, em escolas públicas do estado de São Paulo. Para aplicação do Jecripe 2 (Brandão et al., 2014) foi utilizado o computador, caixa de som e fone de ouvido. Além disso, foram utilizados materiais de papelaria para registro dos dados e das avaliações. Foi utilizado um celular com câmera para filmagem de $30 \%$ das sessões. 
Tabela 2. Descrição das tarefas em cada ambiente do JECRIPE

\begin{tabular}{ll}
\hline Fases do jogo & Tarefas \\
\hline No sítio com & H1.1 - Identificar o lugar em que \\
os animais & cada animal está a partir do som que \\
ele produz. & H1.2 - Identificar o animal a partir \\
& de instrução oral (por exemplo, \\
& "encontre o pato"), e Inserir o \\
& animal em seu habitat natural (por \\
& exemplo, inserir o pato no lago). \\
& H1.3 - Identificar as frutas \\
& disponíveis por meio de pareamento \\
& por identidade.
\end{tabular}

$\begin{array}{ll}\begin{array}{l}\text { No } \\ \text { apartamento }\end{array} & \begin{array}{l}\text { H2.1 }- \text { Rastreamento visual, por } \\ \text { exemplo, "clique na Manu para } \\ \text { saber onde ela está olhando" }\end{array} \\ & \text { H2.2 - Quebra-cabeças com fundo } \\ & \text { (pareamento por identidade entre } \\ \text { figuras) } & \\ \text { Na praia } & \text { H3.1 - Identificar objetos por } \\ & \text { categoria, por exemplo, selecione os } \\ & \text { itens para levar à praia }\end{array}$

H3.2 - Correspondência entre som e figura

\section{Resposta esperada (a ser dada pelo estudante)}

Com base na fala do locutor do jogo, espera-se que o estudante siga a instrução, por exemplo: "passe a mãozinha nos patos, os patos ficam na lagoa".

Com base na fala do locutor do jogo, espera-se que o estudante selecione o animal correspondente à instrução oral e, depois, arrastasse até o lago a partir da instrução: "Coloque o patinho no lago".

A resposta esperada é que, sem qualquer dica oral, o estudante arrastasse a fruta citada pelo locutor, em conjunto às demais frutas, por exemplo, a maçã deveria ser posta em uma cesta que já continha maçãs.

Com base na dica visual do jogo, espera-se que o estudante consiga identificar quem é a personagem Manu, assim como seguir a instrução do locutor: "Clique na Manu para saber onde está olhando".

A resposta esperada é que o estudante, com base na dica visual do jogo (pareamento por identidade entre figuras), complete o quebra-cabeças.

A orientação geral é dada pelo locutor: "coloque os objetos de praia na bolsa de praia". A resposta esperada é que o estudante identifique, selecione e arraste os objetos adequados à praia para dentro da bolsa.

A resposta esperada é que o estudante siga a instrução do locutor de associar e manipular o som já ouvido com a sua fonte.

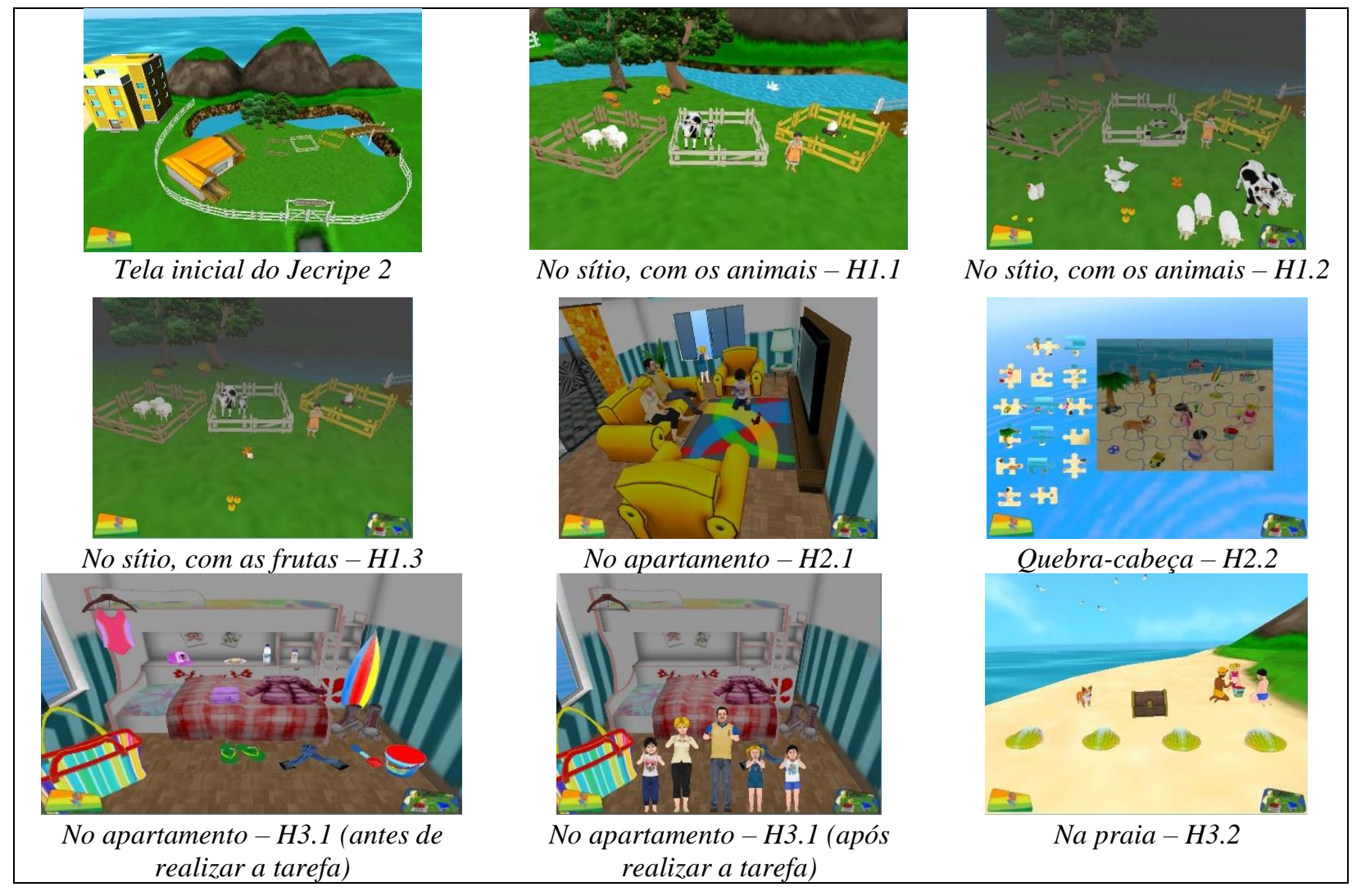

Figura 1. Ilustração das tarefas, de acordo com as fases do JECRIPE 


\subsection{Variáveis e Delineamento Experimental}

A variável independente estabelecida foi a forma de aplicação do Jecripe 2, com uso de sua versão original, disponível online para download, sem nenhuma modificação, no contexto do AEE, em escolas públicas, monitorado pela professora do AEE, na presença do pesquisador. A variável dependente foi o desempenho de cada estudante nas tarefas propostas em cada fase do jogo, por meio de um delineamento experimental comumente utilizado em pesquisas na área da Educação Especial, do tipo A-B-A (Cozy, 2009). A significa linha de base (pré-teste), aplicação da variável independente (no caso, Jecripe 2) sem qualquer dica adicional; B significa aplicação do Jecripe 2 na presença da professora de educação especial, fornecendo dicas nas tarefas do jogo, durante o AEE; A retorno à linha de base (pós-teste).

\subsection{Procedimento de ensino}

$\mathrm{O}$ experimento foi composto por quatro fases, descritas a seguir.

2.5.1 Seleção e avaliação do repertório de entrada dos estudantes público-alvo da educação especial e da professora do AEE

Foi realizado o contato com a Secretaria Municipal de Educação de uma cidade da região metropolitana de São Paulo, para indicação de uma escola que fornecia o AEE em sala de recursos multifuncional. Ademais, também foi realizado o contato com uma Escola Estadual com o mesmo perfil. Assim, foi realizada uma conversa com a professora do AEE e na ocasião foram apresentados os objetivos do estudo, o funcionamento do Jecripe 2 e as tarefas de ensino. $\mathrm{Na}$ sequência, foram indicados os estudantes para aplicação da linha de base. $\mathrm{O}$ critério estabelecido pela professora foi referente ao baixo ou nulo vocabulário expressivo dos estudantes. Os pais assinaram o Termo de Consentimento Livre e Esclarecido, e então foi aplicada a linha de base.

\subsubsection{Aplicação da linha de base (pré-teste)}

Os estudantes jogaram o Jecripe 2 sem nenhuma dica adicional. $\mathrm{O}$ pesquisador aplicou a linha de base na presença da professora do AEE. A aplicação do experimento foi conduzida pelo primeiro pesquisador na presença da professora do AEE. Os estudantes A4, A5, A6, A7 e A8 responderam corretamente $100 \%$ das tarefas e, por essa razão, não seguiram para Fase 3.

\subsubsection{Aplicação do Jecripe 2 pelo professor de educação especial (ensino)}

O Jecripe 2 foi aplicado pela professora de educação especial durante o AEE. Todas as aplicações foram realizadas na presença do pesquisador. Durante a aplicação, o pesquisador registrou todas as interações realizadas entre professora do AEE e estudante para posterior análise, tal qual o desempenho do estudante em cada tarefa proposta no Jecripe 2. O pesquisador também registrou os acertos e erros dos estudantes em cada atividade, uma vez que o jogo não apresenta pontuação e nem registro de desempenho automático.

\subsubsection{Reavaliação da linha de base (pós-teste)}

E, por último, os estudantes jogaram sem nenhuma instrução adicional (pós-teste), da mesma forma como ocorreu na Fase 1. Além disso, foi avaliada a percepção da professora em relação ao jogo por meio de uma conversa não estruturada, na qual o pesquisador registrou suas impressões sobre o uso do Jecripe 2 como possível estratégia de ensino a ser utilizada no AEE. 


\subsection{Análise de dados}

Os dados foram analisados seguindo a lógica do delineamento de sujeito único, de maneira individualizada, com o objetivo de aferir o progresso de cada estudante ao longo do jogo. Os desempenhos dos estudantes foram mensurados em cada fase do procedimento em termos de aprendizagem e não aprendizagem, para tal, foi realizado um cálculo denominado como taxa de aprendizado.

$$
A=\left(\frac{1-\left(T-T_{\min }\right)}{T_{\max }-T_{\min }}+\frac{1-\left(E-E_{\min }\right)}{E_{\max }-E_{\min }}\right) \cdot \frac{100}{2}
$$

$\mathrm{A}=$ taxa de aprendizado $(\%)$

$\mathrm{T}=$ Tempo em segundos para realização da atividade pelo estudante (caso se enquadre entre o limite máximo e mínimo)

$\mathrm{E}=$ Erros cometidos pelo estudante (caso se enquadre entre o limite máximo e mínimo)

$\mathrm{T}_{\min }, \mathrm{T}_{\max }, \mathrm{E}_{\min }, \mathrm{E}_{\max }=$ Limites mínimo e máximo, respectivamente, do tempo e do erro atribuído à tarefa.

Para cada tarefa foi proposto um limite de tempo para emissão de respostas. Os critérios utilizados para considerar que o aluno não aprendeu (atribuiu-se automaticamente $\mathrm{A}=0 \%$ ): ultrapassar o tempo máximo e/ou o limite máximo de erros, apresentados na tabela 3, assim como ter necessitado de intervenção direta do pesquisador ou da professora, ou seja, tenha sido necessário que pegassem o mouse e concluíssem a atividade; caso contrário submeteram-se seus resultados ao cálculo da taxa de aprendizagem, resultando em aprendizagem total ( $\mathrm{A} \geq 100 \%$, automaticamente $\mathrm{A}=100 \%)$ ou parcial $(0 \%<\mathrm{A}<100 \%)$. Caso o aluno permanecesse sem reação frente ao comando dado pelo jogo, assim como quando estimulado por dicas do pesquisador e/ou da professora, por mais de 20 segundos, o desempenho era classificado como sem resposta (s.r).

A Tabela 3 descreve as variáveis presentes no cálculo de aprendizagem proposto para cada tarefa do jogo.

Tabela 3. Cálculo de aprendizagem para cada tarefa

\begin{tabular}{ll}
\hline Tarefa & Cálculo de aprendizagem \\
\hline $\mathrm{H} 1.1$ & $\left(\mathrm{~T}_{\min }=1: 00 / \mathrm{T}_{\max }=2: 00 / \mathrm{E}_{\min }=2 / \mathrm{E}_{\max }=4\right)$ \\
$\mathrm{H} 1.2$ & $\left(\mathrm{~T}_{\min }=0: 50 / \mathrm{T}_{\max }=1: 40 / \mathrm{E}_{\min }=2 / \mathrm{E}_{\max }=4\right)$ \\
$\mathrm{H} 1.3$ & $\left(\mathrm{~T}_{\min }=0: 40 / \mathrm{T}_{\max }=1: 20 / \mathrm{E}_{\min }=3 / \mathrm{E}_{\max }=6\right)$ \\
$\mathrm{H} 2.1$ & $\left(\mathrm{~T}_{\min }=0: 15 / \mathrm{T}_{\max }=0: 30 / \mathrm{E}_{\min }=1 / \mathrm{E}_{\max }=2\right)$ \\
$\mathrm{H} 2.2$ & $\left(\mathrm{~T}_{\min }=2: 00 / \mathrm{T}_{\max }=4: 00 / \mathrm{E}_{\min }=5 / \mathrm{E}_{\max }=10\right)$ \\
$\mathrm{H} 3.1$ & $\left(\mathrm{~T}_{\min }=1: 15 / \mathrm{T}_{\max }=2: 30 / \mathrm{E}_{\min }=3 / \mathrm{E}_{\max }=6\right)$ \\
$\mathrm{H} 3.2$ & $\left(\mathrm{~T}_{\min }=1: 30 / \mathrm{T}_{\max }=3: 00 / \mathrm{E}_{\min }=2 / \mathrm{E}_{\max }=4\right)$ \\
\hline
\end{tabular}

A taxa de aprendizagem foi utilizada para que permitisse uma análise numérica mais próxima do desempenho do estudante, considerando a variável tempo e respostas corretas. Atribuiu-se às tarefas em que o tempo necessário para a conclusão tenha sido entre o limite mínimo e máximo (estabelecido para cada tarefa), tanto para o tempo quanto para o erro.

Os limites mínimos do tempo foram traçados embasados nos resultados das aplicações dois e três (aplicações com auxílio) dos estudantes A1, A2 e A3 (que realizaram todo o procedimento). Já para os erros, o limite mínimo foi estipulado a partir da quantidade de comandos que deveriam ser seguidas ou a quantidade de objetos que deveriam ser correlacionados; o seu limite mínimo foi, de forma geral, marcado como metade dos comandos 
seguidos ou dos itens a serem correlacionados. Para ambos os limites máximos, foram utilizados o dobro do respectivo limite mínimo.

É importante destacar que os erros foram contabilizados caso o aluno tenha feito um movimento considerado como errado, ou seja, questões motoras tais como: clique indevido, não permanência do dedo pressionado no botão do mouse e cliques múltiplos, não foram registrados.

Para avaliar a interação entre a professora de educação especial e o estudante, foi conduzida uma análise da interação da díade a partir de observações sistemáticas realizadas pelo pesquisador e registro no diário de campo. A análise dos registros evidenciou que, quando o estudante não respondia imediatamente após a instrução dada pelo jogo, ou ainda, ao errar as atividades, a professora do AEE fornecia dicas como forma de orientá-lo para realizar a atividade de maneira correta. As dicas dadas para os estudantes foram analisadas conforme Benitez e Domeniconi (2012) a partir de três categorias: oral, gestual e física.

\section{Resultados}

Os resultados foram apresentados em três categorias, são elas: 1) desempenho quantitativo dos estudantes em cada tarefa do Jecripe 2,2 ) registros realizados na interação entre professora do AEE, estudante e pesquisador, 3) feedback dado pela professora do AEE sobre o Jecripe 2. Os estudantes A4, A5, A6, A7 e A8 responderam corretamente 100\% das tarefas na primeira aplicação que tinha como função avaliar o repertório de entrada (pré-teste) e, por essa razão, não foram expostos às fases subsequentes. A Figura 2 mostra o desempenho de A1 (diagnóstico de microcefalia vera e deficiência intelectual) nas quatro aplicações.

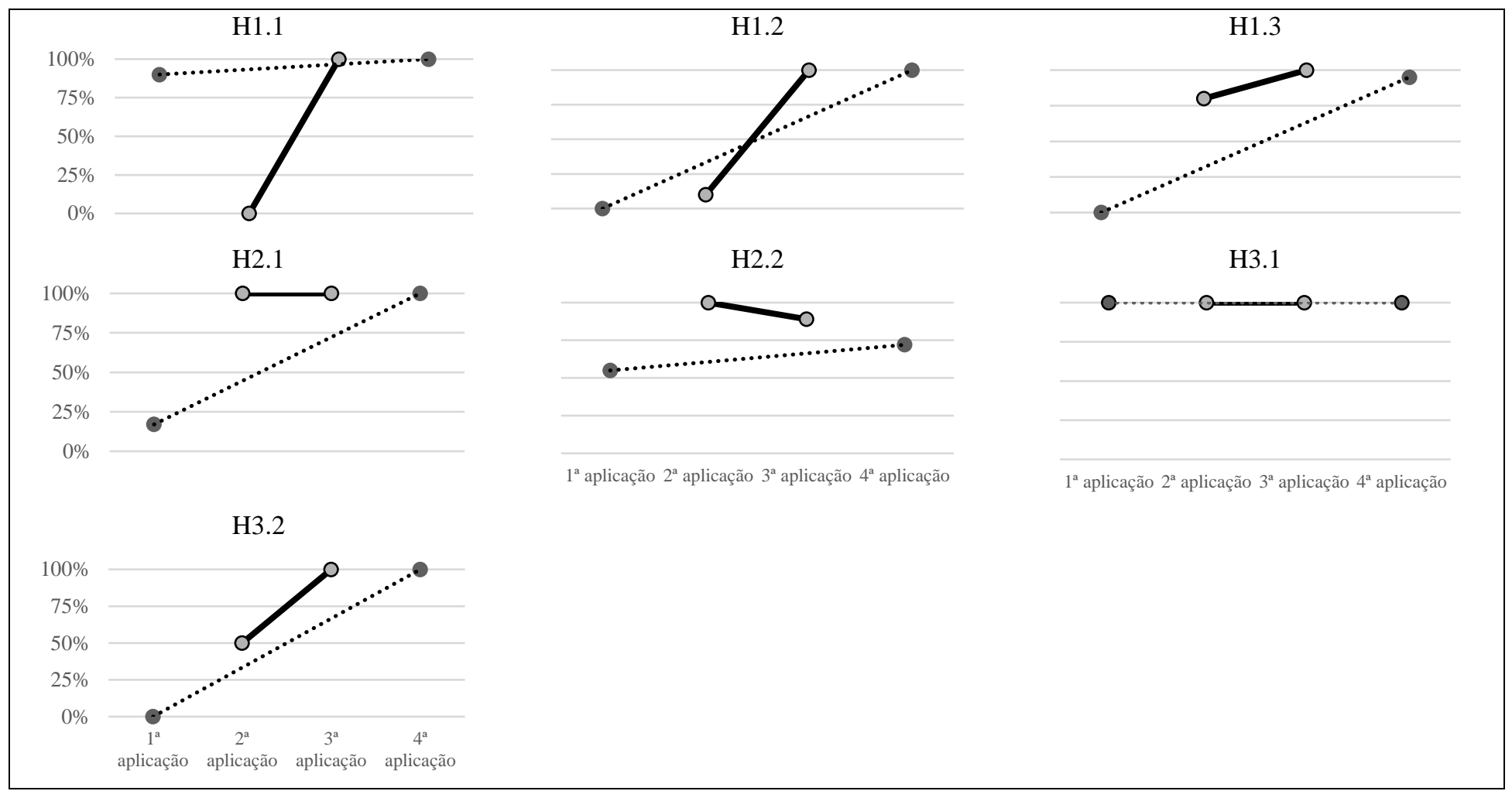

Figura 2. Desempenho de A1 de acordo com a taxa de aprendizagem em cada fase do procedimento de ensino. A linha pontilhada se refere às aplicações sem auxílio, e a linha contínua, às aplicações com auxílio. 
A Figura 3 mostra o desempenho de A2 (diagnóstico de microcefalia vera e deficiência intelectual) nas tarefas de ensino.

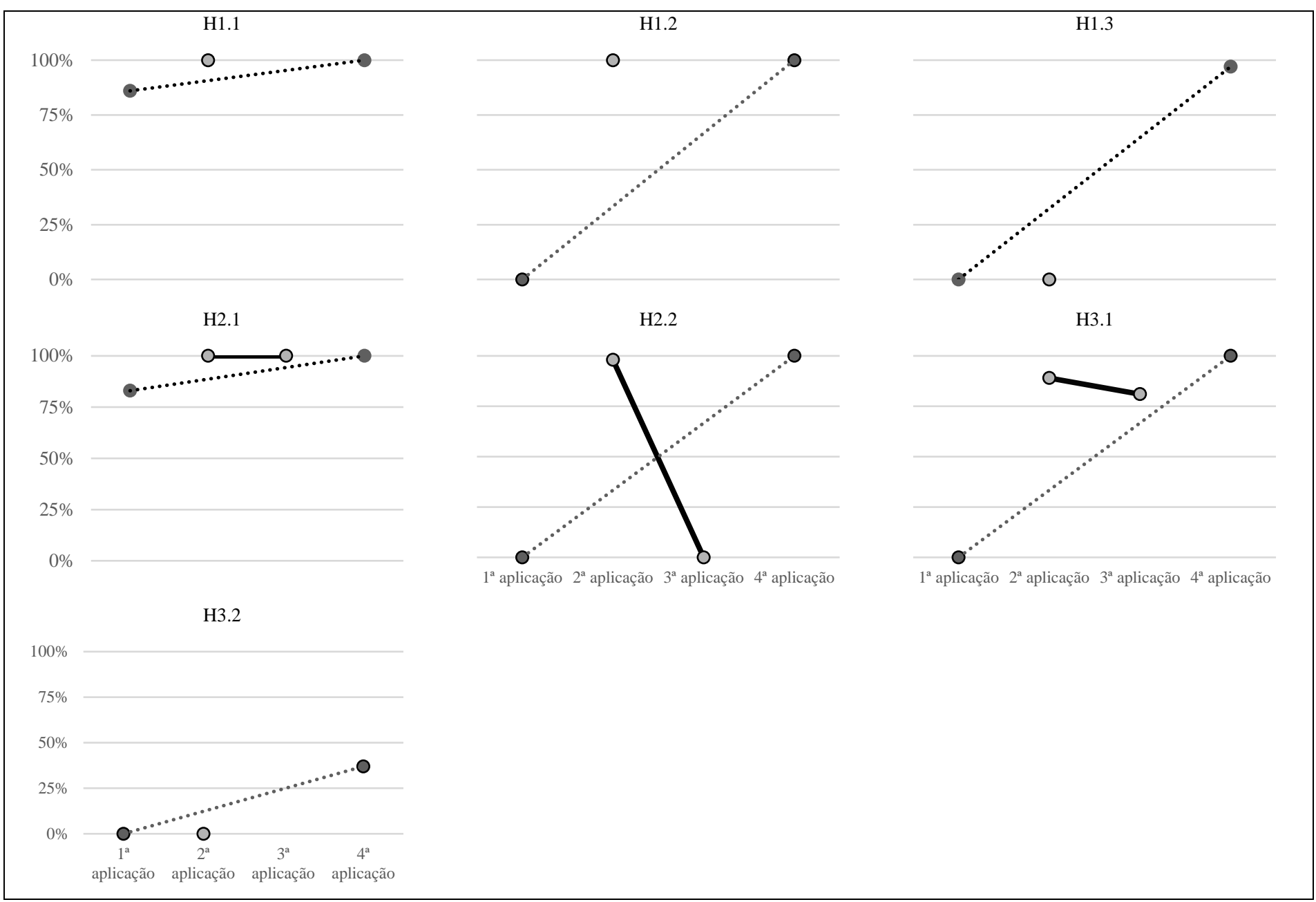

Figura 3. Desempenho de A2 de acordo com a taxa de aprendizagem em cada fase do procedimento de ensino. A linha pontilhada se refere às aplicações sem auxílio, e a linha contínua, às aplicações com auxílio.

As atividades H1.1, H2.1, H3.1 e H4.2 não foram aplicadas devido às variáveis ambientais presentes durante a aplicação, como interrupção da atividade. De maneira geral, na quarta aplicação o estudante apresentou maior desempenho em relação à primeira para todas as atividades do Jecripe 2 .

A Figura 4 mostra o desempenho de A3 (diagnóstico de hemofilia B e deficiência intelectual) nas tarefas de ensino. Nesse caso, é fundamental explicar que A3 realizou apenas as sessões com dicas, no caso, a segunda aplicação e a terceira aplicação, por uma falha de aplicação durante o procedimento de coleta de dados. 


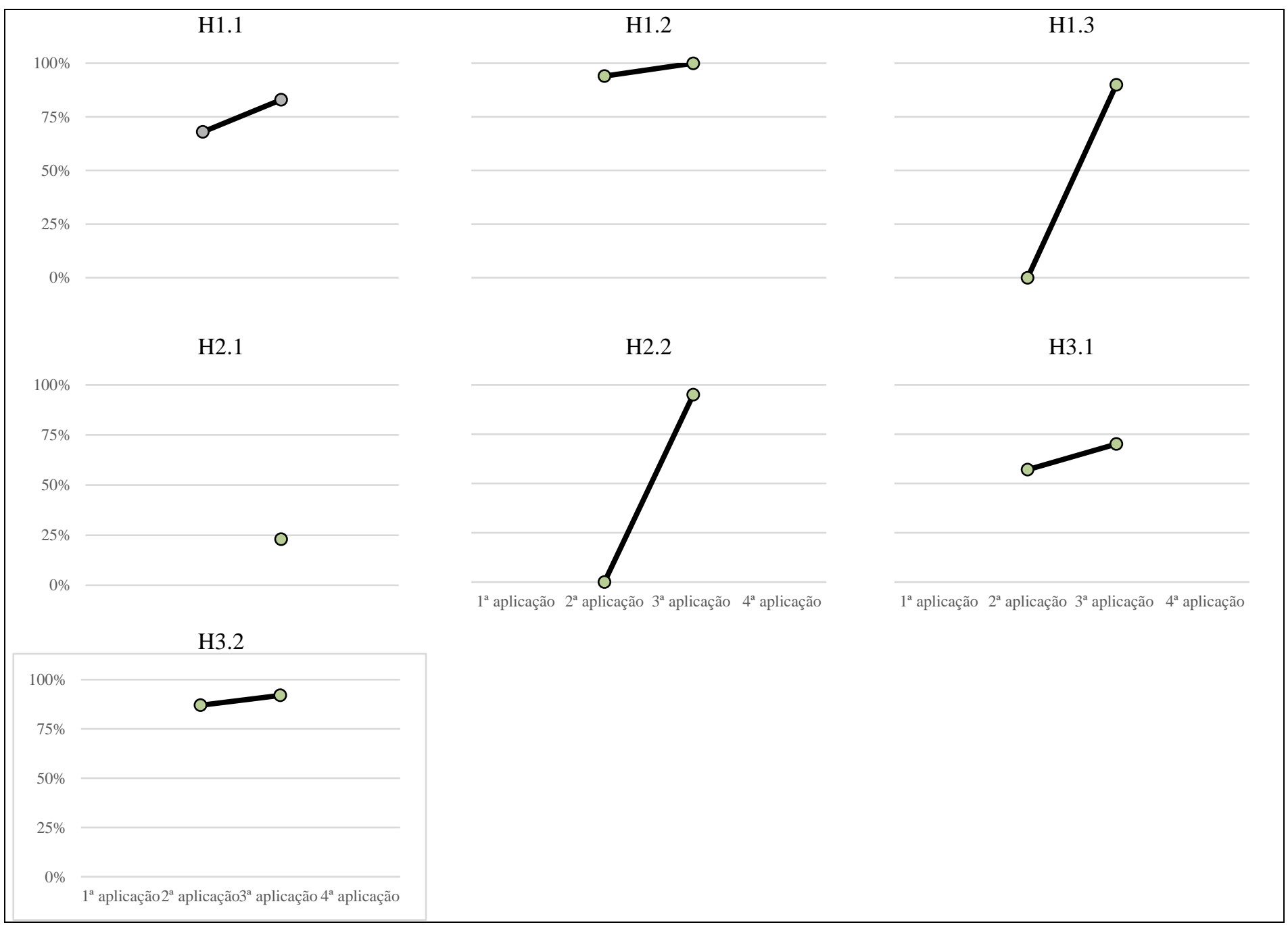

Figura 4. Desempenho de A3 de acordo com a taxa de aprendizagem em cada fase do procedimento de ensino. A linha pontilhada se refere às aplicações sem auxílio, e a linha contínua, às aplicações com auxílio.

Em relação aos registros realizados pelo pesquisador durante a aplicação do Jecripe 2, foi observado que A1 sentiu-se desconfortável com a presença do pesquisador na primeira aplicação. Nas aplicações (segunda e terceira) com dica, seja do pesquisador ou da professora, notou-se que as dicas que geraram maior número de respostas corretas foram as gestuais, sejam elas focadas diretamente na resposta, ou na região aproximada dela. Notou-se que o estudante aplicava em alguns exercícios a estratégia de tentativa de acerto e erro, principalmente na primeira aplicação, em que ele respondia sem necessariamente ter compreendido a instrução.

A2 (diagnóstico de microcefalia vera e deficiência intelectual) apesar de ter errado em algumas atividades tanto na primeira quanto na quarta aplicação, ao analisar o seu desempenho geral, é perceptível a evolução gradual de acertos em todas as tarefas que foi exposto. Também é importante destacar que o estudante não executou todas as tarefas na terceira aplicação. $\mathrm{O}$ estudante apresentou respostas corretas quando utilizadas dicas gestuais, apesar de que em alguns exercícios essa dica não tenha sido suficiente, seja por dificuldades motoras, seja por dificuldades decorrentes do próprio jogo, como por exemplo, a pouca luminosidade na fase do jogo que previa a organização das frutas na fazenda. Já as dicas verbais foram efetivas em alguns exercícios como o H2.1 e H3.1. 
Vale destacar que A3 (diagnóstico de hemofilia B e deficiência intelectual), com exceção da atividade H3.2 na segunda aplicação, foi classificado como apto ao projeto apenas pelo quesito tempo, isto é, caso o aluno resolvesse em tempo hábil, seria retirado do projeto por ter tido todas, ou a maioria, das atividades como corretas. É igualmente importante destacar que, dentre os três alunos selecionados, A3 foi aquele que apresentou maior número de acertos em todas as tarefas do Jecripe 2, mas também o que mais necessitou da repetição do comando dado pelo computador, ou seja, a dica mais efetiva foi a oral que não acrescentava nenhuma informação além daquela já dita pelo próprio jogo.

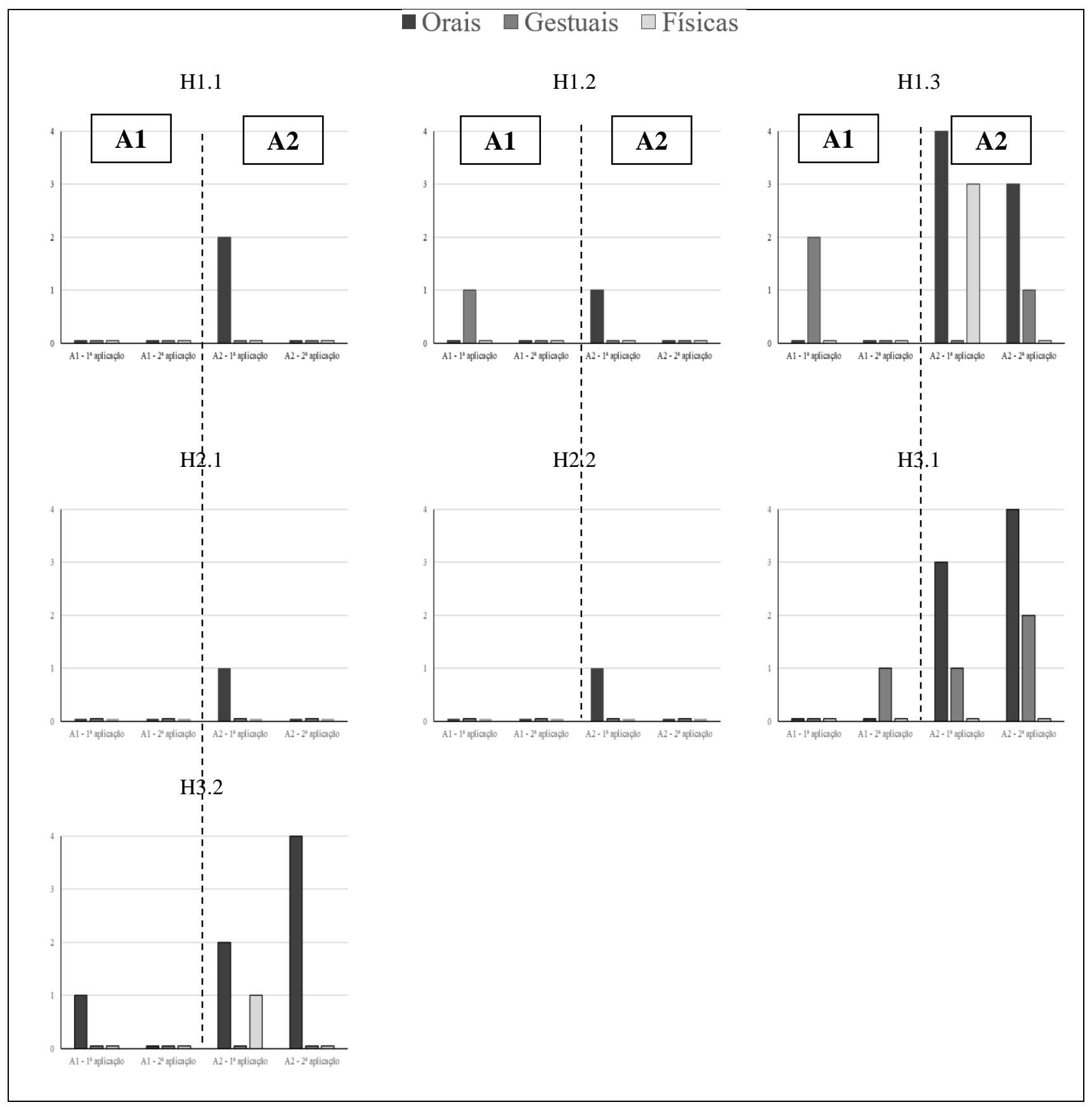

Figura 5. Quantificação das dicas dadas pela professora do AEE durante a aplicação do JECRIPE na segunda e terceira aplicação com A1 e A2. 
A Figura 5 quantifica o tipo de dicas dado pela professora do AEE durante aplicação do Jecripe 2, em cada atividade, para cada estudante. Todas as dicas foram registradas e analisadas em três categorias: orais, gestuais e físicas, de acordo com os achados de Benitez e Domeniconi (2012).

Exemplos de dicas foram registradas, a destacar: a) para H1.1 - dicas orais: “Onde está o pato?", "Onde está a ovelha?", b) H1.2 - dica gestual apontando para o lago, dica oral: "Cadê o pato?", c) H1.3 - dicas gestuais para a região da árvore, dicas orais: "Aí não é o lugar das maçãs", "Que cor é a maçã?", "Está vendo a árvore?", "Está vendo que aqui tem um monte de laranja?", dica gestual apontando para a região da resposta correta, dicas físicas para uso do mouse, para arrastar a figura na posição correta, d) H2.1 - dica oral: "Quem é a Manu?", f) H2.2 - dica oral: "Para onde você deve arrastar?", h) H3.1 - dica oral: "Você vai levar a blusa para praia?", "Esse item não é apropriado para praia", dica gestual apontando para a região da resposta correta; i) H3.2 - dica oral: "Esse é o som da criança?", "Já ouviu o som do mar?", "E dos passarinhos?", "Esse não é o som do cachorro", "A concha com o som das crianças já foi utilizada", "Ó, ouve o barulho", dica física para manter o mouse pressionado e arrastá-lo até a resposta correta.

A professora do AEE foi questionada ao final da coleta de dados sobre suas impressões referentes ao jogo em relação a três categorias básicas: 1) pontos positivos, 2) pontos que precisam de melhorias, 3) sugestões. Segundo a professora, o jogo traz uma gama de pontos positivos, das quais destacam-se: os comandos dados são específicos para cada tarefa, facilitando sua execução, a interação das atividades, assim como o feedback dado pelas personagens ao concluir a tarefa; a possibilidade de ir do prédio ao sítio e à praia, contextualizando o estudante no ambiente, assim como a intercomunicação entre a atividade e seu contexto. Também citou pontos para melhoria do programa como: a curva de aprendizado não apresenta desafios maiores quando já alcançada a aprendizagem; na fase do sítio, após a tempestade, poderia clarear a tela; há a chance de o estudante não ter tido contato com a praia ou com o sítio, dificultando uma associação com suas experiências de vida. Apesar dos pontos de melhoria, disse que o jogo serviria para uma parcela de estudantes do AEE e que para atingir o desenho universal deveria ser traduzido para Língua Brasileira de Sinais - Libras, de modo a envolver também os estudantes surdos. Segundo ela, o Jecripe 2 serviria para trabalhar conceitos de organização (H2.2, H2.3, 4.1) e promover uma inclusão digital.

\section{Discussões e Conclusões}

O presente estudo buscou avaliar se o uso de um jogo digital sério seria suficiente para avaliar e ensinar vocabulário em uma situação naturalística de ensino a partir da perspectiva do professor do AEE, com estudantes com repertórios comportamentais variados (como no caso, deficiência intelectual, síndrome de Down, transtorno do espectro autista e paralisia cerebral). Dos oito estudantes, cinco (A4 - diagnóstico de paralisia cerebral, A5 e A6 - diagnóstico de síndrome de Down e deficiência intelectual severa, A7 e A8 - transtorno do espectro autista) responderam corretamente $100 \%$ das tarefas na primeira aplicação e, por essa razão, não foram expostos às fases subsequentes, o que significa que já tinham aprendido tais atividades em momentos anteriores e, com isso, não justificava ensiná-los novamente.

Para os outros três (A1 e A2 - diagnóstico de microcefalia vera e deficiência intelectual e A3 - diagnóstico de hemofilia B e deficiência intelectual) os resultados mostraram mudanças nos desempenhos de cada um deles ao comparar as primeiras aplicações com as últimas aplicações para cada atividade (H1.1 - A1 de 0\% para 100\%; A2 de 86\% para $100 \%$; A3 de $68 \%$ para $83 \%$ de acertos; H1.2 - A1 e A2 de $0 \%$ para $100 \%$ e A3 de $94 \%$ para $100 \%$; H1.3 - 
A1 de $0 \%$ para $95 \%$; A2 de $0 \%$ para $97 \%$ e A3 de $0 \%$ para $90 \%$; $\mathrm{H} 2.1$ - A1 de $17 \%$ para $100 \%$ e A2 de $83 \%$ para $100 \%$; H2.2 - A1 de $55 \%$ para $72 \%$; A2 de $0 \%$ para $87 \%$ e A3 de $0 \%$ para 95\%; H3.1 - A1 manteve o mesmo desempenho ( $\mathrm{n}=100 \%)$; A2 de $0 \%$ para $100 \%$ e A3 de $57 \%$ para $70 \%$; H3.2 - A1 de 0\% para 100\%; A2 de 0\% para 37\% e A3 de $87 \%$ para $92 \%$ ).

O propósito do trabalho não foi comparar os desempenhos de vocabulário expressivo e receptivo como realizado em estudos anteriores (Araujo et al., 2010; Armonia et al., 2015; Nalom et al., 2015), mas de seguir as recomendações dadas em cada um deles, no sentido de garantir condições para avaliação e ensino do vocabulário receptivo. Assim, o estudo buscou investigar procedimento se o uso de um jogo digital poderia provocar efeitos no vocabulário receptivo em estudantes público-alvo da educação especial, dada a importância desse tipo de capacidade no desenvolvimento da linguagem e, principalmente, por ser um preditivo importante para o ensino de habilidades mais complexas, como a leitura com compreensão (Colombo, \& Carnio, 2018; Nalom et al., 2015).

A escolha do Jecripe 2 ocorreu em função de ser um jogo desenvolvido e fundamentado em dados sólidos de pesquisa (Brandão et al., 2014) que ainda não continha um dado de aprendizagem com estudantes com diferentes repertórios comportamentais, diferentes idades e modalidades de ensino. Outro ponto também se referiu ao fato de o jogo ter sido desenvolvido a luz das recomendações de um jogo sério, como uma equipe interdisciplinar com organização sistemática (Rocha et al., 2016). No presente estudo, foi garantido o aspecto transversal da educação especial (Brasil, 2008), no sentido de trabalhar com estudantes que cursavam a educação infantil (A7), o ensino fundamental (A5, A6 e A8), o ensino médio (A4) e a EJA (A1, A2, A3). Todos eles jogaram o mesmo jogo, com resultados diferentes de desempenho para cada tarefa. Isso mostra que o Jecripe 2 pode ser considerado enquanto estratégia pedagógica que pode contribuir com a premissa do desenho universal (Brasil, 2004, 2016). Recomenda-se que o jogo seja bilíngue, no sentido de garantir também as instruções em Libras, conforme orientação da professora do AEE participante do estudo.

Apesar de poucos participantes (A1, A2 e A3) terem concretizado todas as aplicações, é visível que o desempenho aumentou significativamente quando comparada à primeira aplicação com a quarta nas Figuras 2, 3 e 4. Ademais, a professora confirmou a hipótese levantada inicialmente sobre o uso do Jecripe 2 enquanto TA (Brasil, 2016) a ser utilizada durante o AEE.

O Jecripe 2 enquanto recurso de TA a ser adotada em sala de recursos multifuncional cria oportunidade para discutir sobre estratégias pedagógicas digitais que possam incrementar o processo de ensino e aprendizagem do público-alvo da educação especial, garantindo práticas inclusivas que ultrapassam as demandas reducionistas nessa área (Espote et al., 2013), além de fomentar a educação especial inclusiva como área interdisciplinar do conhecimento, com diálogo direto à Informática na Educação. Recomenda-se que estudos futuros possam fazer uma avaliação de follow up para verificar se a professora de AEE utilizou o jogo com os estudantes pensando na manutenção e generalização da aprendizagem.

Em termos de dicas fornecidas para os estudantes, A2 $(n=33)$ foi o que precisou de maior número de dicas em comparação a $\mathrm{A} 1(\mathrm{n}=3)$. E a tarefa em que foi dado o maior número de dicas foi H1.2 ( $n=13)$, seguida da H3.1 $(n=11)$ e H3.2 $(n=8)$. De acordo com a análise das dicas dadas, sobretudo as orais, podem ser consideradas como comportamentos adequados do professor e do pesquisador na interação com cada estudante, pois se referiam na maioria das vezes ao fornecimento de instrução adicional da tarefa, de acordo aos achados de Benitez e Domeniconi (2012).

A variabilidade de diagnósticos dos estudantes foi importante para garantir o uso transversal de todo o público-alvo na perspectiva do desenho universal (Brasil, 2004; 2016; Zerbato \& 
Mendes, 2018). Recomenda-se que estudos futuros apliquem uma avaliação sistemática de desenvolvimento de vocabulário como medida de avaliação do repertório de entrada para todos os estudantes.

As tarefas propostas no Jecripe 2 envolveram instruções orais com estímulos visuais, com tarefas diversificadas que de alguma forma exigiam que o estudante emitisse respostas de compreensão conforme as instruções eram apresentadas (Araujo et al., 2010). Tais tarefas portanto se referem ao vocabulário receptivo dadas tais características. Na atividade H1.2, que exigia a identificação do animal a partir da instrução oral, os três tiveram $100 \%$ de acertos nas ultimas aplicações. Já as tarefas que envolviam pareamento por identidade, como H1.3 e H2.2, apesar de os três estudantes terem apresentados desempenhos maiores nas aplicações finais, eles não atingiram 100\% de acertos (H1.3 - 97\%, 95\%, 90\% e H2.2 - 87\%, 72\%, 95\%). A comparação dos desempenhos da atividade $\mathrm{H} 1.2$ com os pareamentos por identidade H1.3 e $\mathrm{H} 2.2$ foram curiosos, pois em geral os estudantes tendem a apresentar $100 \%$ de acertos nas tarefas de identidade, por serem consideradas como mais elementares e esperarem que os estudantes relacionem os estímulos, em função das características por similaridade física, em relação ao desempenho na atividade $\mathrm{H} 1.2$ que exige um pareamento arbitrário entre palavra falada e figura.

Dentre os aspectos propostos para melhoria do jogo, destacam-se: qualidade das imagens, pois algumas vezes o cachecol foi confundido com calça; os patins também foram uma imagem que gerou dúvida durante a atividade, se deveria ser levado ou não à praia, considerando o aspecto lúdico dos calçadões para respectiva utilização; e, por último, as frutas, uma vez que a macieira foi citada apenas uma única vez antes da atividade e de forma imperceptível, adicionando-se a isto, a tela escura apresentou-se como obstáculo à conclusão da atividade.

Vale ressaltar que a falta de alguns comandos exigiu a intervenção do professor ou do pesquisador durante a tarefa, pois caso contrário, o estudante não sabia o que fazer no jogo devido à falta de instrução em algumas etapas como, por exemplo, na tela inicial da ilha, em que não aparece nenhuma instrução para o estudante, no sentido de instrui-lo a selecionar um ambiente para início das atividades. Outra tela que careceu de instrução foi na tarefa de ouvir os sons da praia (H3.2), em que não é dada nenhuma instrução para o estudante continuar. Entende-se que tais situações podem parecer intuitivas do ponto de vista da jogabilidade, entretanto para garantir o uso do jogo com diferentes públicos, torna-se importante acrescentar tais instruções em versões posteriores. Assim, as limitações identificadas no Jecripe 2 replicaram os desafios tecnológicos encontrados na revisão da literatura de Araújo et al (2013), ao analisar oito softwares desenvolvidos no contexto da educação inclusiva, de modo que seja necessário propor adaptações que visem atender as particularidades de cada estudante, independentemente do rótulo diagnóstico apresentado por cada um deles.

Assim sendo, o jogo mostrou-se como ferramenta útil a ser aplicada pelos professores de educação especial, ao longo do AEE, nas escolas regulares, visando o ensino de vocabulário receptivo, conforme relatado pela professora do AEE participante do estudo. Considerando a comunicação como um desafio ao processo inclusivo (Camargo, 2017; Togashi \& Walter, 2016), o Jecripe 2 criou oportunidade para ampliação do vocabulário receptivo dos três estudantes ao comparar o repertório de entrada (primeiras aplicações) ao de saída (últimas aplicações). 


\section{Referências}

Araújo, M. V. M. et al. (2010). Avaliação do vocabulário receptivo de crianças préescolares. Estudos de Psicologia (Campinas), 27(2), 169-176. doi: 10.1590/S0103$\underline{166 \times 2010000200004}$

Armonia, A. C. M. et al. (2015). Relação entre vocabulário receptivo e expressivo em crianças com transtorno específico do desenvolvimento da fala e da linguagem. Revista CEFAC, 17(3), 759-765. doi: 10.1590/1982-021620156214

Benitez, P., \& Domeniconi, C. (2012). Verbalizações de familiares durante aprendizagem de leitura e escrita por deficientes intelectuais. Estudos de Psicologia, 29(4), 553-563. doi: 10.1590/S0103-166X2012000400010.

Benitez, P., \& Domeniconi, C. (2016). Consultoria colaborativa: estratégias para o ensino de leitura e escrita. Psicologia: teoria e prática, 18(3), 141-155. doi: 10.5935/19806906/psicologia.v18n3p141-155

Brasil. (2004). Decreto $n^{\circ}$ 5.296, de 2 de dezembro de 2004. Regulamenta as leis 10.048 e 10.098 de 2000. Disponível em: http://www.planalto.gov.br/ccivil_03/_ato20042006/2004/decreto/d5296.htm. Acesso em: 24 fev. 2019.

Brasil. (1996/2013). Lei 9394/96-Lei de Diretrizes e Bases da Educação Nacional. Disponível em: http://www.planalto.gov.br/ccivil_03/leis/L9394.htm. Acesso em: 24 fev. 2019.

Brasil. (2016). Decreto no 13.146, de 6 de julho de 2015. Institui a Lei Brasileira de Inclusão da Pessoa com Deficiência (Estatuto da Pessoa com Deficiência). 2015. Disponível em: http://www.planalto.gov.br/ccivil_03/_Ato2015-2018/2015/Lei/L13146.htm. Acesso em: 10 abr. 2017.

Brandão, A., Brandão, L., Nascimento, G., Moreira, B., Vasconcelos, C. N., Clua, E. (2010a). JECRIPE: stimulating cognitive abilities of children with Down Syndrome in pre-scholar age using a game approach. Proceedings of the 7th International Conference on Advances in Computer Entertainment Technology, 15-18. doi: 10.1145/1971630.1971635

Brandão, A., Trevisan, D., Brandão, L., Moreira, B., Nascimento, G.,Vasconcelos, C. N., Clua, E. \& Mourão, P. (2010b). Semiotic Inspection of a Game for Children with Down Syndrome. Brazilian Symposium on Games and Digital Entertainment, Florianopolis, 199210. doi: 10.1109/SBGAMES.2010.24

Brandao, A. L., Fernandes, L. A. F., Trevisan, D., Clua, E., \& Strickery, D. (2014). Jecripe: how a serious game project encouraged studies in different computer science areas. IEEE 3nd International Conference on Serious Games and Applications for Health (SeGAH), 1-8. doi: $\underline{10.1109 / \text { SeGAH.2014.7067077 }}$

Brandão, A., \& Joselli, M. (2015). Jecripe 2: estimulação da memória, atenção e sensibilização fonológica em crianças com Síndrome de Down. In Proceedings of the XIV Brazilian Symposium on Games and Digital Entertainment, SBGAMES (Vol. 15, pp. 518-525).

Brasil. (2008). Política Nacional de Educação Especial na perspectiva da Educação Inclusiva. Disponível em: http://portal.mec.gov.br/index.php?option=com_docman\&view=download\&alias=16690politica-nacional-de-educacao-especial-na-perspectiva-da-educacao-inclusiva-

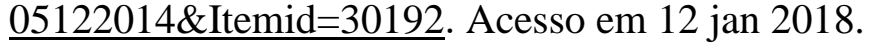

Camargo, E. P. (2017). Inclusão social, educação inclusiva e educação especial: enlaces e desenlaces. Ciência \& Educação, 23(1), 1-6. doi: 10.1590/1516-731320170010001 
Cardoso, A. et al. (2013). Tabuada Legal: um jogo sério para o ensino de multiplicações. Anais do II Congresso Brasileiro de Informática na Educação (CBIE 2013), 376-385. doi: 10.5753/CBIE.SBIE.2013.376

Colombo, R. C., \& Cárnio, M. S. (2018). Compreensão de leitura e vocabulário receptivo em escolares típicos do ensino fundamental I. CoDAS, 30(4), 1-8. doi: $10.1590 / 2317-$ $\underline{1782 / 20182017145 .}$

Cozby, P. C. (2009). Métodos de Pesquisa em Ciências do Comportamento (P. I. C. Gomide, E. Otta, \& J. de O. Siqueira, Transl.). São Paulo: Atlas.

Espote, R., Serralha, C. A., \& Scorsolini-Comin, F. (2013). Inclusão de surdos: revisão integrativa da literatura científica. Psico-USF, 18(1), 77-88. doi: 10.1590/S1413$\underline{82712013000100009}$

Freire, P. (1996). Pedagogia da autonomia: saberes necessários à prática educativa. São Paulo: Paz e Terra.

Freitas, V. C. B., \& Adamatti, D. (2016) Educa Direito: Um Jogo Sério para o Ensino de Direito do Trabalho. Revista Brasileira de Informática na Educação, 24(3), 1-15. doi: 10.5753/rbie.2016.24.3.1

Mendes, E. G. (2019). A Política de Educação Inclusiva e o Futuro das Instituições Especializadas no Brasil. Arquivos Analíticos de Políticas Educativas, 27 (22).

Nalom, A. F. O. et al. (2015). A relevância do vocabulário receptivo na compreensão leitora. CoDAS, 27(4), 333-338. doi: 10.1590/2317-1782/20152015016

Rocha, R. V. et al. (2016). Metodologia de Desenvolvimento de Jogos Sérios: especificação de ferramentas de apoio open source. Revista Brasileira de Informática na Educação, 24(3), 109-124. doi: 10.5753/rbie.2016.24.3.109

Rosa, D. L. (2007). A Escola e a Formação do Sujeito Moral: Possibilidades e Limites da Instituição Escolar. Revista entre ideias: educação, cultura e sociedade, 6(5), 13-26. doi: 10.9771/2317-1219rf.v6i5.2835

Togashi, C. M., \& Walter, C. C. F. (2016). As Contribuições do Uso da Comunicação Alternativa no Processo de Inclusão Escolar de um Aluno com Transtorno do Espectro do Autismo. Revista Brasileira de Educação Especial, 22(3), 351-366. doi: 10.1590/S1413$\underline{65382216000300004 .}$ 